\title{
POTENCIAL PRODUTIVO DE LINHAGENS DE AMENDOIM DO GRUPO ERETO PRECOCE COM E SEM CONTROLE DE DOENÇAS FOLIARES ${ }^{(1)}$
}

\author{
IGNÁCIO JOSÉ DE GODOY ${ }^{(2,7)}$; SÉRGIO ALMEIDA DE MORAES ${ }^{(3,7)}$; ANDREA \\ ROCHA ALMEIDA DE MORAES ${ }^{(2,8)}$; FRANCISCO SEIITI KASAI ${ }^{(4)}$; ANTONIO \\ LÚCIO MELLO MARTINS ${ }^{(5)}$; JOSÉ CARLOS VILA NOVA ALVES PEREIRA ${ }^{(6)}$
}

RESUMO

Avaliaram-se o potencial produtivo, o rendimento de grãos após descascamento e a massa de grãos de onze linhagens de amendoim (Arachis hypogaea L.) do programa de melhoramento do Instituto Agronômico e da cultivar IAC-Tatu-ST, com e sem controle de doenças foliares. O material genético classifica-se no grupo ereto precoce (A. hypogaea subsp. fastigiata, Waldron). Seis experimentos foram desenvolvidos na época das águas, no Núcleo de Agronomia da Alta Mogiana e na Estação Experimental de Agronomia de Pindorama, em 1994/95, 1995/96 e 1996/97, em esquema com duas parcelas subdivididas, em blocos ao acaso com quatro repetições, em que as parcelas principais consistiram em tratamentos com e sem o controle químico das doenças. As parcelas tratadas foram pulverizadas periodicamente com 3,0 L.ha ${ }^{-1}$ do fungicida chlorothalonil para controle da mancha-castanha e da mancha-preta (Cercospora arachidicola e Cercosporidium personatum) e da verrugose (Sphaceloma arachidis). A ausência de controle químico resultou em significativas reduções, até de $60 \%$, na produção de todos os genótipos. Com as doenças controladas, as linhagens IAC 5, IAC 21, IAC 22 e IAC 81-12 apresentaram maior potencial produtivo, atingindo $5.000 \mathrm{~kg} \cdot \mathrm{ha}^{-1} \mathrm{em}$ dois dos experimentos. As linhagens IAC 81-7 e IAC 88-1 apresentaram os melhores desempenhos relativos entre as médias de ambientes com e sem controle químico. As doenças causaram reduções até de $14 \%$ no peso médio dos grãos, sobretudo nas linhagens IAC 5, IAC 21 e IAC 22, cujos grãos são de maior tamanho médio. Não foram observadas diferenças significativas em rendimento de grãos entre os tratamentos, na maioria dos ambientes; essa característica mostrou, também, ser pouco influenciada pela presença das doenças. Palavras-chave: amendoim, Arachis hypogaea subsp.. fastigiata Waldron, linhagens, potencial produtivo, controle de doenças foliares.

\section{ABSTRACT \\ YIELD POTENTIAL OF UPRIGHT EARLY MATURING PEANUT LINES WITH AND WITHOUT CONTROL OF FOLIAR DISEASES}

Eleven peanut lines and the cultivar IAC-Tatu-ST, of the upright early maturing group (Arachis hypogae subsp. fastigiata, Waldron), were evaluated for pod yield, shelling percentage and average kernel weight in six field experiments carried out at the Ribeirão Preto and Pindorama Experiment

$\left({ }^{1}\right)$ Trabalho parcialmente financiado pela FAPESP. Recebido para publicação em 30 de janeiro e aceito em 3 de julho de 2001.

$\left({ }^{2}\right)$ Centro de Plantas Graníferas, Instituto Agronômico (IAC), Caixa Postal 28, 13001-970 Campinas (SP). E-mail: ijgodoy@cec.iac.br

(3) Centro de Fitossanidade, IAC.

(4) Núcleo de Agronomia da Alta Paulista, IAC, Caixa Postal 191, 17800-000 Adamantina (SP).

$(5)$ Estação Experimental de Agronomia de Pindorama, IAC, Caixa Postal 24, 15830-000 Pindorama (SP).

${ }^{6}$ ) Núcleo de Agronomia da Alta Mogiana, IAC, Caixa Postal 271, 14001-970 Ribeirão Preto (SP).

(7) Com bolsa de produtividade em pesquisa do $\mathrm{CNPq}$.

$\left({ }^{8}\right)$ Bolsista da FAPESP. 
Stations of Instituto Agronômico, State of São Paulo, Brazil, during the 1994/95, 1995/96 and 1996/97 growing seasons. Experiments used a split plot design where the main plots consisted of spraying and not spraying fungicides to control foliar diseases. Treated plots were periodically sprayed with 3.0 L.ha $^{-1}$ of chlorothalonil to control early and late leafspots (Cercospora arachidicola and Cercosporidium personatum) and scab (Sphaceloma arachidis). Absence of disease control resulted in significant up to $60 \%$ yield reductions in all genotypes. Where diseases were controlled, the lines IAC 5, IAC 21, IAC 22 and IAC 81-12 showed the highest yield potential, reaching $5.000 \mathrm{~kg} \cdot \mathrm{ha}^{-1}$ in two experiments. Lines IAC 81-7 and IAC 88-1 presented superior relative performance along the environments with and without disease control. Diseases caused reductions in average kernel weight of up to $14 \%$, especially in lines IAC 5, IAC 21 and IAC 22 whose kernel weights ranked highest. Differences in shelling percentage between genotypes were generally not significant. This character was also showed less influenced by foliar diseases.

Key words: peanut, Arachis hypogaea subsp.. fastigiata Waldron, inbred lines, yield potential, disease control.

\section{INTRODUÇÃO}

O amendoim cultivado (Arachis hypogaea L.) compreende as subespécies hypogaea e fastigiata, segundo classificação botânica. Esses grupos diferem entre si por um conjunto de caracteres morfológicos das plantas. Botanicamente, os representantes nativos da subespécie fastigiata são ainda classificados nas variedades fastigiata e vulgaris (KRAPOVICKAS e GREGORY, 1994).

Com a expansão do seu cultivo, as cultivares de fastigiata passaram a ser vulgarmente conhecidas por grupos, Valência e Spanish, para diferenciá-las, principalmente, pelo padrão comercial das vagens, número de sementes por vagem e tamanho das sementes. Esses genótipos apresentam em comum, entre outras características, o hábito de crescimento ereto, e um padrão de ramificação com formação de vagens em uma seqüência contínua ao longo dos ramos primários, resultando em plantas precoces, com ciclo de 90 a 110 dias, da semeadura à maturação.

No Brasil, cultivares descendentes da subespécie hypogaea (GoDor et al., 1996), de porte rasteiro e ciclo longo (130 dias), estão sendo introduzidas nos sistemas de produção totalmente mecanizados, em regiões sem limitação quanto à disponibilidade de chuvas, ou onde não há restrições impostas pelos esquemas de rotação com outras culturas. Cultivares do grupo ereto precoce são as mais disseminadas nas diversas regiões brasileiras onde predominam pequenos produtores (GoDor et al., 1999b). Em sistemas de produção em que a colheita é manual ou semimecanizada, as plantas de porte ereto são as mais indicadas. A precocidade é requerida nas regiões onde o amendoim é cultivado em rotação com a cana-deaçúcar, e é um atributo vantajoso no controle de doenças ou de outros fatores de estresse (MORAES et al., 1994).

No Estado de São Paulo, diversas cultivares do grupo Valência ou oriundas de cruzamentos entre
Valência e Spanish têm sido obtidas, visando aumentar a produtividade da cultura ou melhorar o tamanho dos grãos, aspecto qualitativo que passou a ser importante para o mercado de amendoim. Incrementos na produtividade foram conseguidos quando comparadas com a tradicional cultivar Tatu, do tipo Valência (PomPeu, 1987; ZANOTto, 1993; INSTITUTO Agronômico, 2000). Em algumas cultivares, melhorou-se significativamente o padrão dos grãos, mas houve redução no rendimento após o descascamento (POMPEU, 1987).

Com a alta produtividade observada nas cultivares do grupo rasteiro (GoDor et al., 1994b; GoDOy et al., 1999a), constatou-se a necessidade de tornar os tipos eretos precoces ainda mais competitivos, por meio de ganhos adicionais na produtividade, associada a um rendimento satisfatório no descascamento e grãos de maior tamanho. Com esse objetivo, onze linhagens selecionadas do programa de melhoramento do Instituto Agronômico foram destacadas. Assim como as cultivares já disponíveis, essas linhagens apresentam suscetibilidade a doenças foliares, que devem ser controladas quimicamente. Entretanto, observa-se que, entre genótipos Valência ou Spanish suscetíveis, podem ocorrer diferenças de comportamento produtivo na presença das doenças, ou seja, maior ou menor tolerância (GoDor et al., 1994a; Moraes et al., 1994). Assim, objetivou-se avaliar o potencial produtivo, o rendimento e a massa média de grãos nas condições de controle e ausência de controle das doenças, em situação natural de campo.

\section{MATERIAL E MÉTODOS}

As onze linhagens e a cultivar IAC-Tatu-ST foram avaliadas em seis experimentos desenvolvidos no período "das águas" de 1994/95, 95/96 e 96/97 na Estação Experimental de Agronomia de Pindorama, em Argissolo Vermelho-Amarelo Eutrófico textura 
arenosa/média A moderado, e no Núcleo de Agronomia da Alta Mogiana - Ribeirão Preto - em Latossolo Vermelho Eutroférrico textura argilosa A moderado. Cada experimento foi instalado em terreno previamente calcariado e, no momento da semeadura, adubado com $250 \mathrm{~kg} \cdot \mathrm{ha}^{-1}$ da fórmula 4-14-8.

O material genético avaliado apresenta as seguintes características de identificação: IAC 5, IAC 21 e IAC 22, resultantes de cruzamento entre a cultivar Tatuí (tipo Spanish) e o germoplasma 5567 (tipo Valência), produzem vagens com duas sementes, de tegumento vermelho (IAC- 5) e castanho (IAC 21 e 22); IAC 81-7 obtida do cruzamento entre a cultivar Tatu e o germoplasma 002 (da coleção do IAC), produz vagens com predominância de três ou quatro sementes de tegumento vermelho; IAC 81-12, resultado do cruzamento entre a cultivar Tatuí e o germoplasma 189 (tipo Spanish), apresenta vagens com duas sementes de tegumento castanho; IAC 88-1, selecionada da cultivar Tatu Branco (Valência), produz vagens de três a quatro sementes de tegumento castanho; IAC 88-2 (tipo Spanish), coletada em região produtora da Alta Paulista, apresenta vagens de duas sementes de tegumento castanho; IAC 1075, selecionada do cruzamento entre os acessos de germoplasma 532 e 32, do tipo Valência, produz vagens de três a quatro sementes de tegumento vermelho; as linhagens IAC 2529, IAC 2532 e IAC 2538, provenientes do cruzamento entre linhagens avançadas do tipo Valência, apresentam vagens de três a quatro sementes de tegumento vermelho. IAC-Tatu-ST é material genético (sementes genéticas mantidas e multiplicadas pelo IAC) correspondente à tradicional cultivar Tatu, do tipo Valência, amplamente difundida no Brasil.

Os experimentos utilizaram esquema de parcelas subdivididas e delineamento experimental de blocos ao acaso com quatro repetições. As parcelas principais consistiram em tratamentos com e sem controle químico de doenças foliares, os quais se denominam, neste trabalho, como $\mathrm{P}$ e $\mathrm{N}$ respectivamente. As subparcelas compreenderam as onze linhagens e a cultivar IAC-Tatu-ST (tipo Valência), comercialmente distribuída a partir de sementes genéticas produzidas pelo IAC, totalizando doze tratamentos.

Os tratamentos em $\mathrm{P}$ receberam quatro pulverizações de fungicida à base de chlorothalonil, na dose de 3,0 L por hectare do princípio ativo ao longo do ciclo, a cada 15 dias, efetuando-se a primeira ao redor de 45 dias após a semeadura. Cada subparcela constituiu-se de duas linhas de $5 \mathrm{~m}$ espaçadas de $60 \mathrm{~cm}$, as quais receberam 75 sementes desbastadas, posteriormente, para 50 plantas por linha, após a emergência.

Prevendo-se as variações locais que normalmente ocorrem com relação às doenças foliares, efetuou-se, nas parcelas não controladas quimicamente, um acompanhamento geral da ocorrência e intensidade das principais doenças em cada experimento, mediante identificação dos sintomas e avaliação visual das doenças, adaptando-se uma escala de intensidades (baixa, média e alta) com base em trabalhos anteriores de avaliação de genótipos. Avaliaram-se, de acordo com o experimento, a mancha-castanha (Cercospora arachidicola) e a mancha-preta (Cercosporidium personatum), segundo MoraEs (1987), e a verrugose (Sphaceloma arachidis), segundo Moraes et al. (1983). Em Ribeirão Preto, 94/95, registrou-se o aparecimento da mancha-castanha e da mancha-preta e da verrugose, todas com intensidade classificada como média; no mesmo local, em 95/96, observaram-se intensidades médias de mancha-castanha e verrugose e baixa intensidade de mancha-preta; em 96/97 (mesmo local), observou-se alta intensidade de verrugose e baixa a média da mancha-castanha e da manchapreta. Em Pindorama, 94/95, verificaram-se apenas baixas intensidades de mancha-preta e verrugose; em 95/96, observou-se a mancha-preta com intensidade de baixa a média; em 96/97, a mancha-castanha predominou, com média intensidade, registrando-se, ainda, baixa intensidade de mancha-preta.

Efetuou-se a colheita em todos os tratamentos, entre 90 e 105 dias da semeadura, conforme o experimento, na época considerada normal para plena maturação das vagens, com base na observação das parcelas onde o controle das doenças foi realizado. Após secagem para redução do teor de umidade das vagens aos níveis apropriados para armazenamento, avaliaram-se, em cada subparcela: a produção em casca (transformada em kg.ha ${ }^{-1}$ ), o rendimento em grãos após descascamento (expresso em percentagem da massa de grãos obtidos de uma amostra de $500 \mathrm{~g}$ de vagens) e a massa de 100 grãos tomados ao acaso.

Os dados foram analisados, inicialmente, por experimento, em parcelas subdivididas, para as três variáveis. Posteriormente, devido ao interesse em observar o desempenho comparativo das linhagens com e sem controle químico, $\mathrm{P}$ e $\mathrm{N}$ respectivamente, efetuaram-se análises da variância dentro de cada uma dessas condições de tratamento. Como as médias, tanto em $\mathrm{P}$ como em $\mathrm{N}$, foram variáveis entre os diversos experimentos, optou-se por analisá-los e discuti-los individualmente.

A verificação da uniformidade das variâncias residuais permitiu que fossem efetuadas, também, as análises conjuntas para cada variável, dentro de $\mathrm{P}$ e de N, para avaliar o desempenho médio das linhagens nas duas condições. Nesse caso, as linhagens compuseram os tratamentos e, para as análises, feitas em blocos ao acaso, utilizaram-se as médias 
experimentais, considerando-se os experimentos como repetições.

Os dados médios de cada linhagem, em $\mathrm{P}$ e em $\mathrm{N}$, em cada experimento, foram ainda utilizados para estimar os percentuais de produção, rendimento e massa de 100 grãos nos tratamentos sem controle de doenças $(\mathrm{N})$, em relação aos respectivos valores observados nos tratamentos $\mathrm{P}$, onde as doenças foram controladas, ou seja, (N/P) x 100. Esses dados foram analisados em blocos ao acaso, considerando-se os experimentos como repetições.

\section{RESULTADOS E DISCUSSÃO}

Os valores de $\mathrm{F}$ para as interações controle de doenças $\mathrm{x}$ linhagens resultaram não significativos, com exceção apenas da variável massa de grãos (MG), em três dos experimentos (Quadro 1). Os efeitos do controle de doenças e de linhagens, isoladamente, foram significativos em todos os experimentos, na variável produção de vagens (PROD). Na variável massa de grãos, o valor de $\mathrm{F}$ foi não significativo apenas para controle de doenças no experimento de
Ribeirão Preto, 96/97. No rendimento de grãos (REND), observaram-se diferenças significativas entre os tratamentos $\mathrm{N}$ e $\mathrm{P}$ em dois dos experimentos. Diferenças significativas entre linhagens foram observadas apenas no experimento de Pindorama, 96/97.

As produções de amendoim em casca (Quadro 2) variaram entre os experimentos, independentemente do ano e do local, mesmo nos tratamentos $(\mathrm{P})$ onde as doenças foram quimicamente controladas. Nesse tratamento, as médias experimentais foram superiores a 4.000 kg.ha ${ }^{-1}$ em Pindorama, 94/95 e 95/96, onde a produtividade foi favorecida pela boa distribuição de chuvas durante o ciclo da cultura. As médias inferiores a 2.000 kg.ha ${ }^{-1}$ em Pindorama e Ribeirão Preto, 96/97, foram atribuídas a infestações de tripes nos primeiros 30 dias do ciclo, o que provocou um atraso no desenvolvimento das plantas, resultando em redução da produtividade. Contudo, a ocorrência da praga foi uniforme em todas as parcelas, não causando prejuízos qualitativos para os objetivos dos experimentos. As médias dos tratamentos $\mathrm{N}$ (sem controle das doenças) foram superiores a $3.000 \mathrm{~kg} \cdot \mathrm{ha}^{-1}$

Quadro 1. Resumo das análises da variância para as variáveis produção de vagens (PROD), rendimento de grãos (REND) e massa de grãos (MG), em experimentos de amendoim desenvolvidos em Pindorama (PD) e Ribeirão Preto Preto (RP) nos anos agrícolas de 1994/95 e 1996/97

\begin{tabular}{|c|c|c|c|c|c|c|c|}
\hline \multirow{2}{*}{ Variável } & \multirow{2}{*}{ Experimento } & \multicolumn{3}{|c|}{ Valores de $\mathrm{F}^{(1)}$} & \multirow{2}{*}{ Médias ${ }^{(2)}$} & \multicolumn{2}{|c|}{ Coeficiente de variação } \\
\hline & & $\begin{array}{l}\text { Controle de } \\
\text { doenças (A) }\end{array}$ & Linhagens (B) & $\begin{array}{c}\text { Interação } \\
\mathrm{A} \times \mathrm{B}\end{array}$ & & Resíduo (A) & Resíduo (B) \\
\hline & & & & & & $\longrightarrow$ & $\longrightarrow$ \\
\hline \multirow[t]{6}{*}{ PROD } & PD 94/95 & $47,5^{* *}$ & $11,2^{* *}$ & $1,8 \mathrm{~ns}$ & 4.072 & 5,1 & 9,5 \\
\hline & PD 95/96 & $140,1^{* *}$ & $11,9^{* *}$ & $0,9 \mathrm{~ns}$ & 4.010 & 3,4 & 9,1 \\
\hline & PD 96/97 & $768,4^{* *}$ & $3,8^{* *}$ & $1,2 \mathrm{~ns}$ & 1.148 & 4,7 & 16,9 \\
\hline & $\mathrm{RP} 94 / 95$ & $151,7^{* *}$ & $3,2^{* *}$ & $1,2 \mathrm{~ns}$ & 2.685 & 5,7 & 16,2 \\
\hline & RP 95/96 & $43,0^{* *}$ & $4,6^{* *}$ & $1,0 \mathrm{~ns}$ & 2.206 & 6,3 & 19,4 \\
\hline & RP 96/97 & $20,2^{*}$ & $3,4^{* *}$ & $1,4 \mathrm{~ns}$ & 1.202 & 12,1 & 14,8 \\
\hline \multirow[t]{5}{*}{ REND } & PD 94/95 & $4,8 \mathrm{~ns}$ & $1,7 \mathrm{~ns}$ & $0,7 \mathrm{~ns}$ & 69,7 & 0,9 & 3,5 \\
\hline & PD 95/96 & $125,9^{* *}$ & $0,9 \mathrm{~ns}$ & $1,9 \mathrm{~ns}$ & 71,7 & 0,7 & 4,7 \\
\hline & PD 96/97 & $37,7^{* *}$ & $2,7^{* *}$ & $1,5 \mathrm{~ns}$ & 67,7 & 0,8 & 3,9 \\
\hline & $\mathrm{RP} 94 / 95$ & $0,4 \mathrm{~ns}$ & $1,0 \mathrm{~ns}$ & $0,4 \mathrm{~ns}$ & 64,0 & 1,9 & 7,0 \\
\hline & RP 96/97 & $2,7 \mathrm{~ns}$ & $0,8 \mathrm{~ns}$ & $0,9 \mathrm{~ns}$ & 54,4 & 5,7 & 17,1 \\
\hline \multirow[t]{5}{*}{ MG } & PD 94/95 & $57,6^{* *}$ & $88,4^{* *}$ & $1,4 \mathrm{~ns}$ & 42,2 & 1,5 & 3,7 \\
\hline & PD 95/96 & $74,2^{* *}$ & $209,2^{* *}$ & $6,5^{* *}$ & 46,2 & 1,0 & 3,3 \\
\hline & PD 96/97 & $102,6^{* *}$ & $65,6^{* *}$ & $2,0^{*}$ & 40,3 & 2,1 & 5,1 \\
\hline & RP 94/95 & $251,5^{* *}$ & $75,1^{* *}$ & $2,0^{*}$ & 45,5 & 1,3 & 4,8 \\
\hline & RP 96/97 & $6,6 \mathrm{~ns}$ & $53,7^{* *}$ & $1,3 \mathrm{~ns}$ & 44,6 & 0,9 & 5,5 \\
\hline
\end{tabular}

$\left({ }^{1}\right)^{*}, * *$ : Significativo a $5 \%$ e $1 \%$ de probabilidade, respectivamente, pelo teste F; ns: Não significativo pelo teste F. $\left({ }^{2}\right)$ Médias: PROD em kg.ha- ${ }^{-1}$, REND em \%; MG em gramas por 100 grãos. 
Potencial produtivo de linhagens de amendoim

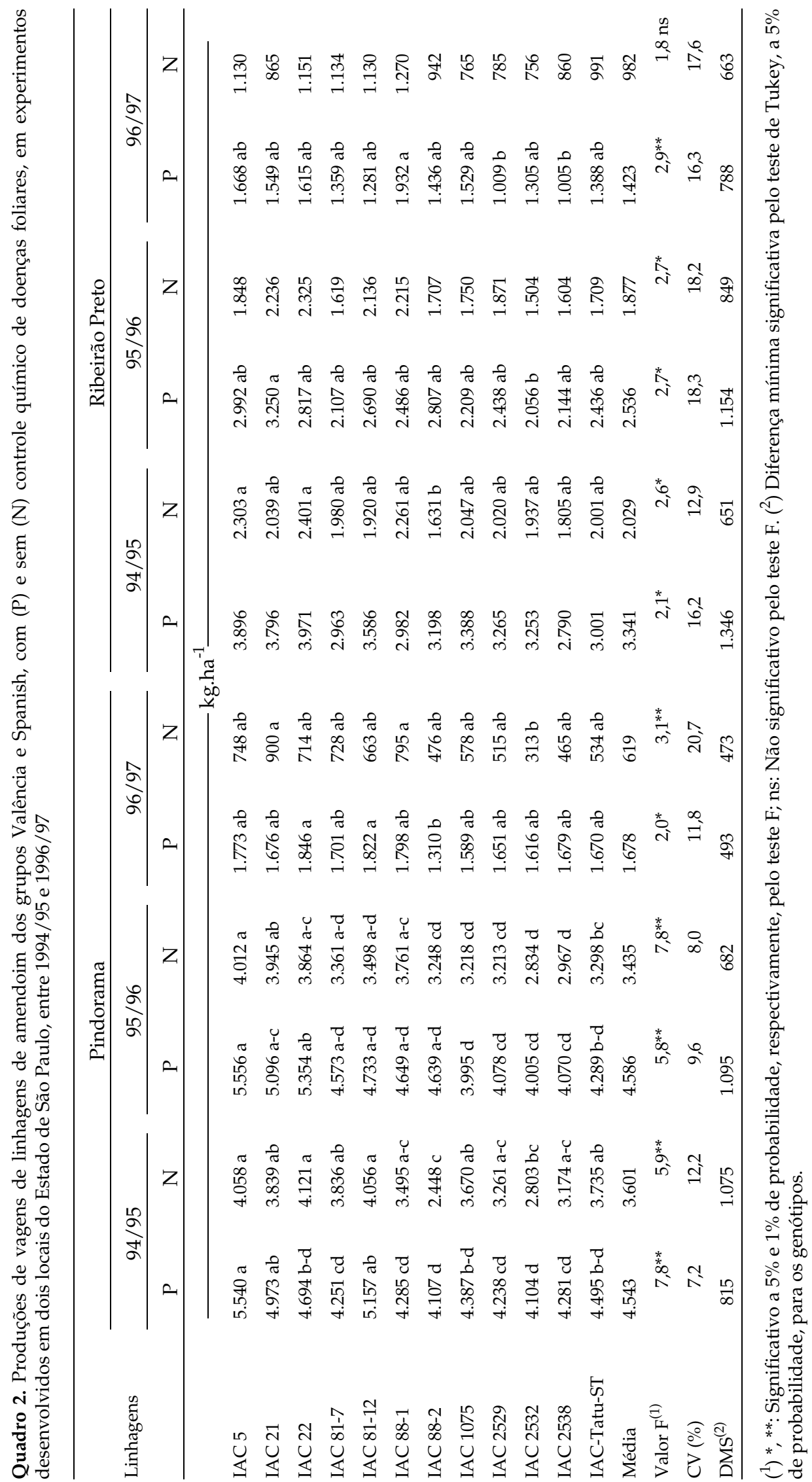

Bragantia, Campinas, 60(2), 101-110, 2001 
em Pindorama, 94/95 e 95/96, e inferiores a $1.000 \mathrm{~kg} \cdot \mathrm{ha}^{-1}$ nos dois locais, em 96/97.

Nos tratamentos $\mathrm{P}$ (com controle químico), as diferenças mais significativas entre as linhagens $(1 \%$ de probabilidade) foram observadas em Pindorama, 94/95 e 95/96 (experimentos de maior produtividade média) e em Ribeirão Preto, 96/97, onde a média foi de 1.423 kg.ha ${ }^{-1}$. Em Pindorama, 94/95, destacaramse as linhagens IAC 5, IAC 81-12 e IAC 21. As duas primeiras produziram acima de $5.000 \mathrm{~kg} \cdot \mathrm{ha}^{-1}$. No mesmo local, em 95/96, nas linhagens IAC 5, IAC 21 e IAC 22, repetiram esse desempenho. Tais dados indicam que as linhagens supracitadas podem atingir produções próximas às de cultivares do tipo rasteiro nas condições do Estado de São Paulo (GoDOY et al., 1996; Godor et al. 1999a), e nos ambientes que favorecem altas produções, superando significativamente as cultivares tradicionais do tipo Valência (ZANOTTO, 1993; Godor et al., 1999a; Instituto Agronômico, 2000).

Nos experimentos de produtividade média mais baixa, as diferenças entre as linhagens foram me- nores; em Pindorama, 96/97, apenas as linhagens IAC 22 e IAC 81-12 diferiram significativamente da IAC $88-2$, a de menor produção; no mesmo ano, em Ribeirão Preto, apenas a linhagem IAC 88-1 (a mais produtiva) diferiu da IAC 2529 e IAC 2538. Em Ribeirão Preto, 94/95, onde a produtividade foi moderada (média de $3.341 \mathrm{~kg} \cdot \mathrm{ha}^{-1}$ ), as linhagens não diferiram entre si, quando as doenças foram controladas; no mesmo local, em 95/96, a linhagem mais produtiva, IAC 21 (com $3.250 \mathrm{~kg} \cdot \mathrm{ha}^{-1}$ ), diferiu apenas da IAC 2532.

A significativa superioridade de algumas das linhagens nos ensaios de produtividade média mais alta pode estar relacionada com o tipo vegetativo (Spanish) de que são originadas, associada ao maior tamanho dos grãos. IAC 81-12 é produto de cruzamento de dois genótipos desse tipo. IAC 5, 21 e 22 resultam de cruzamentos em que um parental é a cultivar Tatuí (Spanish), cujas avaliações de produtividade, em diversos anos e locais mostram que essa cultivar expressa elevado potencial produtivo em

Quadro 3. Rendimentos de grãos após descascamento ${ }^{(1)}$ em linhagens de amendoim dos grupos Valência e Spanish, com (P) e sem (N) controle químico de doenças foliares, em experimentos desenvolvidos em dois locais do Estado de São Paulo, entre 1994/95 e 1996/97

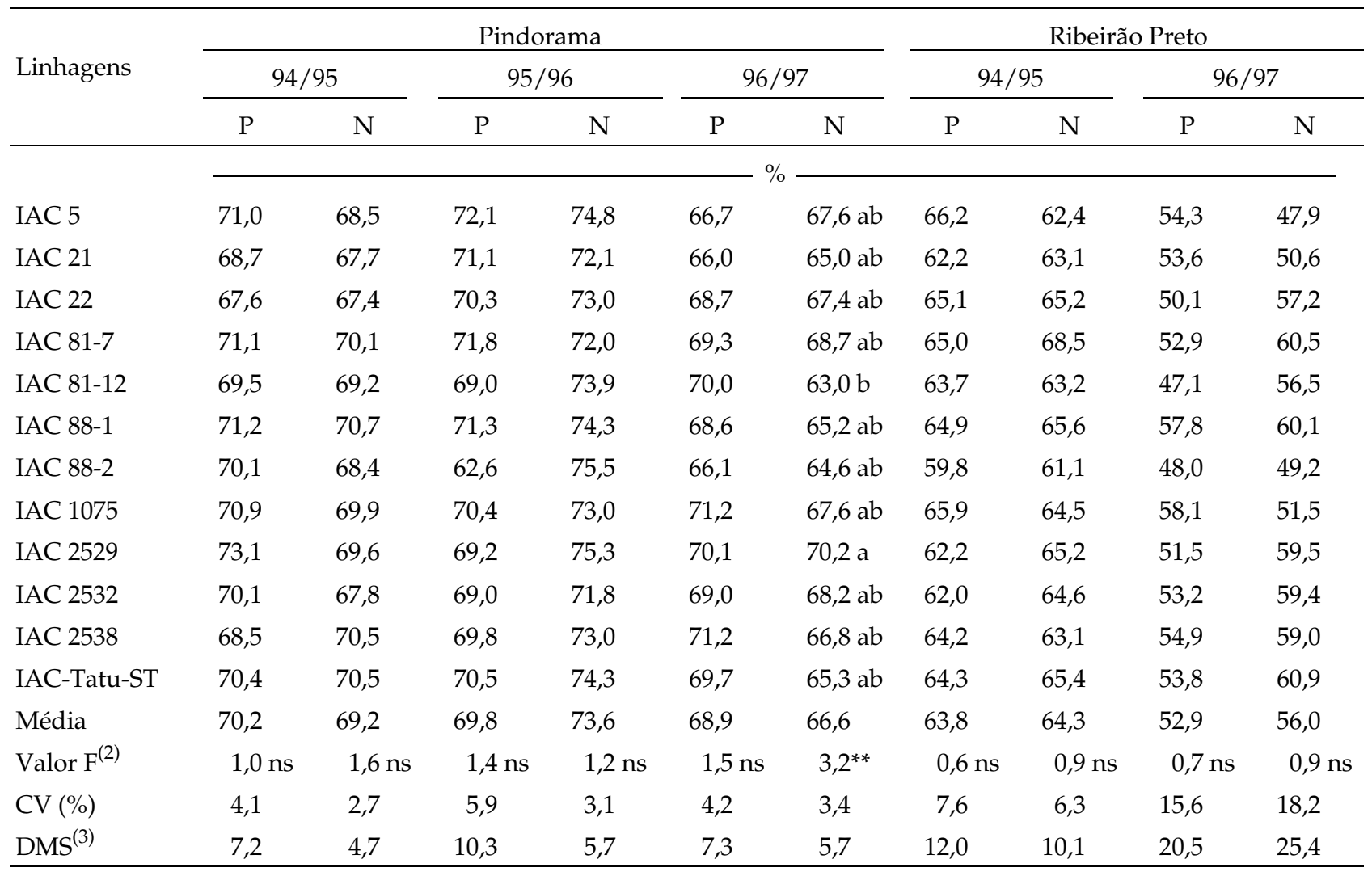

$\left({ }^{1}\right)$ Porcentagem, em massa, dos grãos obtidos após descascamento, em relação à massa em casca. $\left({ }^{2}\right)^{*}$, **: Significativo a $5 \%$ e $1 \%$ de probabilidade, respectivamente, pelo teste F, para os genótipos; ns: Não significativo pelo teste F. $\left({ }^{3}\right)$ Diferença mínima significativa pelo teste de Tukey, a 5\% de probabilidade, para os genótipos. 
ambientes onde as produções são mais altas (GoDOY et al., 1990). Outras cultivares obtidas de cruzamentos envolvendo a cv. Tatuí também apresentam esse comportamento (POMPEU, 1987).

Nos tratamentos $\mathrm{N}$ (sem controle químico), em Pindorama, 94/95 e 95/96, onde a pressão das doenças foi menor, as produções médias dos experimentos ultrapassaram $3.000 \mathrm{~kg} . \mathrm{ha}^{-1}$, mesmo na ausência de controle químico das doenças. As linhagens 22, IAC 5 e IAC 81-12 foram as que mais se destacaram em 94/95, com médias superiores a $4.000 \mathrm{~kg} \cdot \mathrm{ha}^{-1}$, não diferindo significativamente de outras que apresentaram produções acima de $3.000 \mathrm{~kg} \cdot \mathrm{ha}^{-1}$. No mesmo local, em 95/96, a linhagem IAC 5 produziu $4.012 \mathrm{~kg} . \mathrm{ha}^{-1}$, não diferindo de IAC 21, IAC 22, IAC 81-7, IAC 81-12 e IAC 88-1, que produziram entre 3.361 e $3.945 \mathrm{~kg} \cdot \mathrm{ha}^{-1}$. Em 96/97, as doenças acentuaram a baixa produtividade nos dois experimentos. Sem o controle químico, as médias das linhagens em $\mathrm{N}$ foram reduzidas em mais de $60 \%$ em relação a $\mathrm{P}$, em Pindorama, e mais de 30\% em Ribeirão Preto. Isso deve ter contribuído para as variações experimentais que resultaram na ausência de significância entre os tratamentos, exceto em Pindorama, onde as linhagens IAC 21 e IAC 88-1 apresentaram produções significativamente superiores à da IAC 2532. Em Ribeirão Preto, 94/95, local em que as doenças causaram perto de $40 \%$ de redução na produtividade média das linhagens, apenas as linhagens IAC 22 e IAC 5 apresentaram produções significativamente maiores do que a IAC 88-2. No mesmo local, em 95/96, as produções variaram entre 1.504 (linhagem IAC 2532) e $2.325 \mathrm{~kg} \cdot \mathrm{ha}^{-1}$ (IAC 22), porém essas diferenças não foram significativas.

$\mathrm{Na}$ análise conjunta dos experimentos (Quadro 5), destacaram-se, em produção, nos tratamentos $\mathrm{P}$, as linhagens IAC 5, IAC 21, IAC 22 e a IAC 81-12. Confirmou-se, portanto, a tendência de melhor desempenho produtivo entre as representantes do grupo Spanish ou resultantes de cruzamentos com este grupo. Na ausência de controle das doenças $(\mathrm{N})$, essas linhagens mantiveram bom desempenho relativo. Entretanto, algumas linhagens Valência (IAC 81-7, IAC 88-1 e IAC 1075), além da cultivar IAC-Tatu-ST, apresentaram produções próximas às daquele grupo.

Quadro 4. Massa de 100 grãos de linhagens de amendoim dos grupos Valência e Spanish, com (P) e sem (N) controle químico de doenças foliares, em experimentos desenvolvidos em dois locais do Estado de São Paulo, entre 1994/95 e 1996/97

\begin{tabular}{|c|c|c|c|c|c|c|c|c|c|c|}
\hline \multirow{3}{*}{ Linhagens } & \multicolumn{6}{|c|}{ Pindorama } & \multicolumn{4}{|c|}{ Ribeirão Preto } \\
\hline & \multicolumn{2}{|c|}{$94 / 95$} & \multicolumn{2}{|c|}{$95 / 96$} & \multicolumn{2}{|c|}{$96 / 97$} & \multicolumn{2}{|c|}{$94 / 95$} & \multicolumn{2}{|c|}{$96 / 97$} \\
\hline & $\mathrm{P}$ & $\mathrm{N}$ & $\mathrm{P}$ & $\mathrm{N}$ & $\mathrm{P}$ & $\mathrm{N}$ & $\mathrm{P}$ & $\mathrm{N}$ & $\mathrm{P}$ & $\mathrm{N}$ \\
\hline IAC 5 & $53 a$ & $50 \mathrm{a}$ & $64 \mathrm{a}$ & $58 \mathrm{a}$ & $55 \mathrm{a}$ & $45 \mathrm{a}$ & $60 \mathrm{a}$ & $53 a$ & $56 a$ & $52 \mathrm{a}$ \\
\hline IAC 21 & $51 \mathrm{a}$ & $47 \mathrm{a}$ & $61 \mathrm{a}$ & $53 \mathrm{~b}$ & $51 \mathrm{a}$ & $46 a$ & $60 a$ & $50 \mathrm{a}$ & $56 a$ & $55 \mathrm{a}$ \\
\hline IAC 22 & $52 \mathrm{a}$ & $48 \mathrm{a}$ & $61 \mathrm{a}$ & $56 \mathrm{ab}$ & $54 \mathrm{a}$ & $46 a$ & $60 a$ & $54 \mathrm{a}$ & $54 \mathrm{a}$ & $54 \mathrm{a}$ \\
\hline IAC 81-7 & $42 \mathrm{bc}$ & $40 \mathrm{~b}$ & $44 \mathrm{c}$ & $42 \mathrm{~cd}$ & $42 \mathrm{bc}$ & $36 \mathrm{bc}$ & $44 \mathrm{~cd}$ & $40 \mathrm{~b}$ & $41 \mathrm{bc}$ & $41 \mathrm{bc}$ \\
\hline IAC 81-12 & $44 \mathrm{~b}$ & $38 \mathrm{~b}$ & $50 \mathrm{~b}$ & $44 \mathrm{c}$ & $45 \mathrm{~b}$ & $36 \mathrm{bc}$ & $51 \mathrm{~b}$ & $42 \mathrm{~b}$ & $43 \mathrm{~b}$ & $46 \mathrm{~b}$ \\
\hline IAC 88-1 & $44 \mathrm{~b}$ & $40 \mathrm{~b}$ & $44 \mathrm{c}$ & $41 \mathrm{~cd}$ & $42 \mathrm{bc}$ & $38 \mathrm{~b}$ & $48 \mathrm{bc}$ & $41 \mathrm{~b}$ & $44 \mathrm{~b}$ & $44 \mathrm{bc}$ \\
\hline IAC 88-2 & $38 \mathrm{~d}$ & $33 c$ & 41 c-e & $38 \mathrm{~d}$ & $35 \mathrm{~d}$ & $30 c$ & $42 \mathrm{~d}$ & $34 \mathrm{c}$ & $36 c$ & $34 \mathrm{~d}$ \\
\hline IAC 1075 & $44 \mathrm{~b}$ & $40 \mathrm{~b}$ & $44 \mathrm{c}$ & $44 \mathrm{c}$ & $41 \mathrm{bc}$ & $35 \mathrm{bc}$ & $45 \mathrm{~cd}$ & $38 \mathrm{bc}$ & $44 \mathrm{~b}$ & $43 \mathrm{bc}$ \\
\hline IAC 2529 & $42 \mathrm{bc}$ & $39 \mathrm{~b}$ & 42 c-e & $41 \mathrm{~cd}$ & $39 \mathrm{~cd}$ & $35 \mathrm{bc}$ & $44 \mathrm{~cd}$ & $39 \mathrm{~b}$ & $41 \mathrm{bc}$ & $43 \mathrm{bc}$ \\
\hline IAC 2532 & $38 \mathrm{~d}$ & $36 \mathrm{bc}$ & 39 e & $39 d$ & $38 \mathrm{~cd}$ & $32 \mathrm{bc}$ & $42 \mathrm{~d}$ & $38 \mathrm{bc}$ & $41 \mathrm{bc}$ & $39 \mathrm{~cd}$ \\
\hline IAC 2538 & $40 \mathrm{~cd}$ & $37 \mathrm{bc}$ & $40 \mathrm{~d}$ & $41 \mathrm{~cd}$ & $39 \mathrm{~cd}$ & $33 \mathrm{bc}$ & $44 \mathrm{~cd}$ & $40 \mathrm{~b}$ & $44 \mathrm{~b}$ & $41 \mathrm{bc}$ \\
\hline IAC-Tatu-ST & $40 \mathrm{~cd}$ & $38 \mathrm{c}$ & $43 \mathrm{~cd}$ & $41 \mathrm{~cd}$ & $40 \mathrm{c}$ & $35 \mathrm{bc}$ & $46 \mathrm{~b}-\mathrm{d}$ & $39 \mathrm{~b}$ & $40 \mathrm{bc}$ & $40 \mathrm{c}$ \\
\hline Média & 44,0 & 40,5 & 47,7 & 44,8 & 43,4 & 37,2 & 48,8 & 42,3 & 45,0 & 44,3 \\
\hline Valor $\mathrm{F}^{(1)}$ & $52,6^{* *}$ & $38,5^{* *}$ & $159,5^{* *}$ & $69,7^{* *}$ & $59,6^{* *}$ & $20,9^{* *}$ & $37,3^{* *}$ & $40,4^{* *}$ & $24,1^{* *}$ & $32,2^{* *}$ \\
\hline CV (\%) & 3,4 & 4,0 & 3,0 & 3,7 & 3,9 & 6,4 & 4,9 & 4,6 & 5,8 & 5,1 \\
\hline $\mathrm{DMS}^{(2)}$ & 3,7 & 4,1 & 3,5 & 4,1 & 4,2 & 6,0 & 5,9 & 4,9 & 6,6 & 5,6 \\
\hline
\end{tabular}

$\left({ }^{1}\right)^{* *}$ : Significativo a $1 \%$ de probabilidade, pelo teste $\mathrm{F}$, para os genótipos. $\left({ }^{2}\right)$ Diferença mínima significativa pelo teste de Tukey, a $5 \%$ de probabilidade, para os genótipos. 
Na comparação das médias de produção entre os tratamentos P e N dentro de cada linhagem (Quadro 5), as produções, nos tratamentos com controle de doenças foram significativamente superiores às dos tratamentos sem controle, o que confirma a suscetibilidade das linhagens às doenças que ocorreram nos experimentos. Entretanto, quando se compararam os percentuais das produções obtidas em $\mathrm{N}$, em relação às produções em $\mathrm{P}$ (Quadro 6), observam-se algumas diferenças entre os tratamentos. A produção média da linhagem IAC 88-2, nos tratamentos N, atingiu somente $57,2 \%$ da média observada em $\mathrm{P}$, diferindo de forma significativa dos percentuais obtidos nas linhagens IAC $81-7$ e IAC $88-1$ (72,2\% e 72,9\% respectivamente). Embora os demais contrastes não tenham sido significativos, as variações observadas nesses percentuais sugerem diferenças quanto à tolerância a doenças. As linhagens, cujos percentuais de $\mathrm{N}$ em relação a $P$ foram maiores, mostraram-se mais tolerantes, ou seja, as produções foram menos afetadas pelas doenças. Considerando-se esta variável, veri- fica-se que vários representantes do grupo Valência, além da linhagem IAC 22 (resultante de cruzamento Valência $x$ Spanish) apresentam ligeira vantagem sobre os demais.

Segundo Russell (1978), define-se como tolerante (a uma praga ou doença) "a planta que é atacada na mesma intensidade de outra, porém sofre menores danos, em produção ou em qualidade". São poucos os trabalhos que relatam tolerância de genótipos de amendoim a doenças.

Em ensaio sob alta intensidade de ferrugem, Godor et al. (1994a) destacaram, entre diversos genótipos eretos precoces, duas linhagens do tipo Valência (suscetíveis à doença) em que a produção de vagens foi significativamente menos reduzida na presença dessa doença. Em ensaios com e sem controle da mancha- preta, MoRAEs et al. (1994) observaram que a cv. Tatuí (Spanish) apresentou maior resposta ao controle químico da doença que a cv. Tatu (Valência).

Quadro 5. Médias das variáveis produção em casca, rendimento e massa de 100 grãos de linhagens de amendoim dos grupos Valência e Spanish, com $(\mathrm{P})$ e sem $(\mathrm{N})$ controle químico de doenças. Resultados das análises conjuntas dos experimentos desenvolvidos entre 1994/95 e 1996/97

\begin{tabular}{|c|c|c|c|c|c|c|}
\hline \multirow[t]{2}{*}{ Linhagens } & \multicolumn{2}{|c|}{ Produção em casca ${ }^{(1)}$} & \multicolumn{2}{|c|}{ Rendimento de grãos } & \multicolumn{2}{|c|}{ Massa de 100 grãos $^{(1)}$} \\
\hline & $\mathrm{P}$ & $\mathrm{N}$ & $\mathrm{P}$ & $\mathrm{N}$ & $\mathrm{P}$ & $\mathrm{N}$ \\
\hline & \multicolumn{2}{|c|}{ kg.ha-1 } & \multicolumn{2}{|c|}{$\%$} & \multicolumn{2}{|c|}{$-\mathrm{g}$} \\
\hline IAC 5 & $3.571 \mathrm{a}, \mathrm{A}$ & $2.350 \mathrm{ab}, \mathrm{B}$ & $66,1 \mathrm{a}$ & 64,2 & $57,6 \mathrm{a}, \mathrm{A}$ & $51,6 \mathrm{a}, \mathrm{B}$ \\
\hline IAC 21 & $3.390 \mathrm{ab}, \mathrm{A}$ & $2.304 \mathrm{ab}, \mathrm{B}$ & $64,3 \mathrm{ab}$ & 63,7 & $55,8 \mathrm{a}, \mathrm{A}$ & $50,2 \mathrm{a}, \mathrm{B}$ \\
\hline IAC 22 & $3.383 \mathrm{ab}, \mathrm{A}$ & $2.429 \mathrm{a}, \mathrm{B}$ & $64,4 \mathrm{ab}$ & 66,0 & $56,2 \mathrm{a}, \mathrm{A}$ & 51,6 a, B \\
\hline IAC 81-7 & $2.826 \mathrm{~cd}, \mathrm{~A}$ & 2.110 a-d, B & 66,0 a & 68,0 & 42,6 b-e & $39,8 \mathrm{bc}$ \\
\hline IAC 81-12 & $3.211 \mathrm{a}-\mathrm{c}, \mathrm{A}$ & $2.234 \mathrm{a}-\mathrm{c}, \mathrm{B}$ & $63,9 \mathrm{ab}$ & 65,2 & $46,6 \mathrm{~b}$ & $41,2 \mathrm{~b}$ \\
\hline IAC 88-1 & $3.022 \mathrm{~b}-\mathrm{d}, \mathrm{A}$ & $2.299 \mathrm{ab}, \mathrm{B}$ & $66,8 \mathrm{a}$ & 67,2 & $44,4 \mathrm{bc}, \mathrm{A}$ & $40,8 \mathrm{~b}, \mathrm{~B}$ \\
\hline IAC 88-2 & $2.916 \mathrm{~b}-\mathrm{d}, \mathrm{A}$ & $1.742 \mathrm{~d}, \mathrm{~B}$ & $61,3 \mathrm{~b}$ & 63,8 & $38,4 \mathrm{e}, \mathrm{A}$ & $33,8 \mathrm{~d}, \mathrm{~B}$ \\
\hline IAC 1075 & $2.849 \mathrm{~cd}, \mathrm{~A}$ & 2.005 a-d, B & 67,3 a & 65,3 & $43,6 \mathrm{~b}-\mathrm{d}$ & $40,0 \mathrm{bc}$ \\
\hline IAC 2529 & $2.780 \mathrm{~cd}, \mathrm{~A}$ & 1.944 b-d, B & $65,2 \mathrm{ab}$ & 68,0 & 41,6 c-e & $39,4 \mathrm{bc}$ \\
\hline IAC 2532 & $2.723 \mathrm{~cd}, \mathrm{~A}$ & $1.691 \mathrm{~d}, \mathrm{~B}$ & $64,7 \mathrm{ab}$ & 66,4 & 39,6 de & $36,8 \mathrm{~cd}$ \\
\hline IAC 2538 & $2.661 \mathrm{~d}, \mathrm{~A}$ & $1.812 \mathrm{~cd}, \mathrm{~B}$ & $65,7 \mathrm{a}$ & 66,5 & 41,4 c-e & 38,4 bc \\
\hline IAC-Tatu-ST & $2.880 \mathrm{~b}-\mathrm{d}, \mathrm{A}$ & $2.045 \mathrm{a}-\mathrm{d}, \mathrm{B}$ & $65,7 \mathrm{a}$ & 67,3 & 41,8 c-e & $38,6 \mathrm{bc}$ \\
\hline Média & 3.018 & 2.080 & 65,1 & 65,9 & 45,8 & 41,8 \\
\hline Valor $\mathrm{F}^{(2)}$ & $7,7^{* *}$ & $7,8^{* *}$ & $3,5^{* *}$ & $2,1^{*}$ & $61,4^{* *}$ & $79,6^{* *}$ \\
\hline CV $(\%)$ & 8,7 & 10,5 & 2,9 & 3,6 & 4,2 & 3,5 \\
\hline $\mathrm{DMS}^{(3)}$ & 520 & 430 & 4,1 & 5,2 & 4,2 & 3,2 \\
\hline
\end{tabular}

$\left(^{1}\right)$ Letras minúsculas, na vertical: teste de Tukey ao nível de 5\% para as médias entre linhagens; letras maiúsculas, na horizontal: significância para as médias de P e N de cada linhagem ao nível de $5 \%$ pelo teste de Tukey. $\left({ }^{2}\right)$ *, ${ }^{* *}$ : Significativo a $5 \%$ e $1 \%$ de probabilidade, respectivamente, pelo teste F; ns: Não significativo pelo teste F. $\left({ }^{3}\right)$ Diferença mínima significativa entre linhagens pelo teste de Tukey, a $5 \%$ de probabilidade. 
O rendimento de grãos (expresso em percentagem) foi avaliado como medida da capacidade de granação das linhagens, resultando em maior produção de grãos após o descascamento (Quadro 3). Embora essa característica seja citada com valores de média a alta magnitude para a herdabilidade no sentido amplo (GoDor et al., 1999b), os resultados aqui obtidos indicam que as variações encontradas são preponderantemente de diferenças ambientais. As médias dos experimentos variaram entre anos e locais, bem como entre os tratamentos $\mathrm{PeN}$. Entretanto, as diferenças entre as linhagens não foram significativas, exceto em Pindorama, 96/97, no tratamento N. Nesse caso, apenas a linhagem IAC 2529 apresentou rendimento significativamente superior ao da IAC 81-12. Na análise conjunta (Quadro 5) também não houve significância para as médias de rendimento de grãos no tratamento $\mathrm{N}$. Somente em $\mathrm{P}$, as linhagens IAC 5, IAC 81-7, IAC 88-1, IAC 1075, IAC 2538 e a cultivar IAC-Tatu-ST apresentaram médias significativamente maiores do que a da IAC 88-2. Quando se compararam os valores de $\mathrm{P}$ e $\mathrm{N}$ dentro de cada linhagem, nenhuma diferença significativa foi encontrada. Embora o controle de doenças tenha produzido valores de F significativos para essa variável em Pindorama, 95/96 e 96/97 (Quadro 1), os percentuais de $\mathrm{N}$ em relação a $\mathrm{P}$ (Quadro 6) foram próximos de 100 entre todas as linhagens, ou seja, na média de diversos ambientes, os rendimentos de grãos não foram significativamente influenciados pelas doenças.

A massa de grãos foi avaliada em cada parcela e expressa, aqui, em gramas por 100 grãos (Quadro 4). Nos tratamentos P, observou-se que as diferenças entre as linhagens se mantiveram entre os diversos experimentos. Notaram-se algumas variações de um experimento para outro, mas as diferenças foram, em grande parte, decorrentes do tamanho de grãos, característico dos genótipos. As linhagens IAC 5, IAC 21 e IAC 22 destacaram-se com massa de grãos significativamente maiores (entre 50 e $60 \mathrm{~g}$ ). A significativa superioridade para essa característica sugere ser esta uma das causas do destacado potencial produtivo dessas linhagens, uma vez que maior tamanho médio de grãos é relatado como um dos componentes de produtividade do amendoim (GoDor et al., 1999b).

A massa de grãos apresentou, também, variações entre experimentos e entre os tratamentos $\mathrm{P}$ e $\mathrm{N}$, indicando que as variações do ambiente também influenciam essa variável. Entre as médias dos experimentos, os valores variaram de 43,4 a $48,8 \mathrm{~g}$, nos tratamentos $\mathrm{P}$, e de 37,2 a $44,8 \mathrm{~g}$ nos N. Comparandose as médias de $\mathrm{N}$ em relação a $\mathrm{P}$, observou-se que o fator "doenças" produziu reduções variáveis na massa de grãos. Em Ribeirão Preto, 96/97, a massa de
Quadro 6. Percentuais ${ }^{(1)}$ de produção em casca, rendimento e massa média de grãos de linhagens de amendoim, obtidos nas parcelas sem controle químico de doenças foliares $(\mathrm{N})$ em relação às parcelas com controle $(\mathrm{P})$

\begin{tabular}{|c|c|c|c|}
\hline Linhagens & $\begin{array}{c}\text { Produção } \\
\text { em casca }\end{array}$ & $\begin{array}{c}\text { Rendimento } \\
\text { de grãos }\end{array}$ & $\begin{array}{c}\text { Massa média } \\
\text { de grãos }\end{array}$ \\
\hline & & $\%$ & - \\
\hline IAC 5 & $62,7 \mathrm{ab}$ & 98,9 & 89,5 \\
\hline IAC 21 & $64,4 \mathrm{ab}$ & 99,9 & 90,1 \\
\hline IAC 22 & $68,8 \mathrm{ab}$ & 100,4 & 91,8 \\
\hline IAC 81-7 & $72,2 \mathrm{a}$ & 100,8 & 93,4 \\
\hline IAC 81-12 & $68,3 \mathrm{ab}$ & 99,0 & 88,9 \\
\hline IAC 88-1 & $72,9 \mathrm{a}$ & 99,9 & 92,0 \\
\hline IAC 88-2 & $57,2 \mathrm{~b}$ & 104,5 & 88,1 \\
\hline IAC 1075 & $65,0 \mathrm{ab}$ & 98,8 & 91,7 \\
\hline IAC 2529 & $67,2 \mathrm{ab}$ & 102,2 & 94,7 \\
\hline IAC 2532 & $58,2 \mathrm{ab}$ & 100,9 & 92,9 \\
\hline IAC 2538 & $66,6 \mathrm{ab}$ & 99,9 & 93,7 \\
\hline IAC-Tatu-ST & $66,7 \mathrm{ab}$ & 100,2 & 92,5 \\
\hline Média & 65,9 & 100,5 & 91,5 \\
\hline Valor $\mathrm{F}^{(2)}$ & $2,4^{*}$ & $0,7 \mathrm{~ns}$ & $1,4 \mathrm{~ns}$ \\
\hline CV (\%) & 11,4 & 3,7 & 4,1 \\
\hline $\mathrm{DMS}^{(3)}$ & 14,9 & 9,3 & 8,2 \\
\hline
\end{tabular}

$\left({ }^{1}\right)$ Obtidos por $(\mathrm{N} / \mathrm{P})$ x 100. Médias dos conjuntos de experimentos avaliados (seis para produções e cinco para rendimentos e massa média de grãos). $\left({ }^{2}\right)$ *: Significativo a $5 \%$ de probabilidade pelo teste F; ns: Não significativo pelo teste F. $\left({ }^{3}\right)$ Diferença mínima significativa entre linhagens pelo teste Tukey, a 5\% de probabilidade.

grãos foi de 45,0 g em P e de 44,3 g em N, uma redução apenas de 1,6\%, mas em Ribeirão Preto, 94/95, e em Pindorama, 96/97, as reduções foram de 13,3\% e $14,3 \%$ respectivamente. No tratamento $\mathrm{N}$ desses experimentos, as linhagens IAC 5, IAC 21 e IAC 22 mantiveram massa de grãos significativamente maior que as demais, mas as reduções em relação a $P$ foram mais pronunciadas. Entre as demais linhagens, algumas das médias que foram significativamente inferiores em P igualaram-se em $\mathrm{N}$, em um grupo intermediário. As maiores reduções nas linhagens de maior massa de grãos podem ser confirmadas na média dos cinco experimentos (Quadro 5) onde, à exceção da linhagem IAC 81-12, os valores médios da IAC 5, IAC 21, IAC 22 e IAC 88-1 em P foram significativamente menores que as respectivas médias em N. A outra exceção foi a linhagem IAC 88-2; apesar dos grãos de menor massa, também apresentou significativa redução devido às doenças, confirmando 
sua falta de tolerância. Não foram observadas diferenças significativas entre os percentuais de $\mathrm{N}$ em relação a P para massa de grãos (Quadro 6), embora se observe que esses valores variaram de 88,1\% (linhagem IAC 88-2) a 94,7\% (linhagem IAC 2529).

\section{CONCLUSÕES}

1. Entre todas as linhagens avaliadas, as doenças são responsáveis por reduções significativas (da ordem até de $60 \%$ ) na produção de vagens e de $14 \%$ na massa de grãos.

2. Em ambientes mais favoráveis, para obtenção de alta produtividade e com controle de doenças foliares, o potencial produtivo das linhagens IAC 5, IAC 21, IAC 22 e IAC 81-12 é da ordem de 5.000 kg.ha-1 de vagens. $\mathrm{Na}$ ausência de controle das doenças, as produções médias das diversas linhagens tendem a ser próximas, podendo atingir $4.000 \mathrm{~kg} \cdot \mathrm{ha}^{-1}$. Neste caso, destacaram-se, além das linhagens acima, as seguintes representantes do grupo Valência: IAC 881, IAC 81-7, IAC 1075 e a cultivar IAC-Tatu-ST.

3. Com as doenças controladas, as linhagens IAC 5, IAC 21 e IAC 22 sobressaíram-se, apresentando massa de 100 grãos entre 50 e 60 g. Na presença de doenças, as linhagens de maior massa de grãos tendem a sofrer as maiores reduções nessa característica.

4. Na média dos experimentos, os genótipos não apresentam diferenças significativas entre si no caráter rendimento de grãos após o descascamento, com e sem controle das doenças. Essa característica mostrou-se variável com o ambiente, porém pouco influenciada pela presença de doenças.

5. Valores significativos, indicadores de tolerância, são observados na produção de vagens. As linhagens Valência IAC 81-7 e IAC 88-1 apresentam os melhores desempenhos relativos entre a média dos ambientes com e sem controle de doenças e, nesse sentido, a linhagem IAC 88-2 pode ser classificada como a de menor tolerância.

\section{REFERÊNCIAS BIBLIOGRÁFICAS}

GODOY,I.J.;MORAES, S.A.; MARTINS, A.L.M.; PEREIRA, J.C.V.N.A. Resistência e tolerância de linhagens e cultivares de amendoim à ferrugem (Puccinia arachidis). Fitopatologia Brasileira, Brasília, v.19, n.4, p.524-531, 1994a.

GODOY, I.J.; MORAES, S.A.; MARTINS, A.L.M.; PEREIRA, J.C.V.N.A.; VEIGA, R.F.A. Avaliação do potencial agronômico de introduções de amendoim com vistas ao melhoramento genético. Bragantia, Campinas, v.49, n.1, p.127-140, 1990.
GODOY, I.J.; MORAES, S.A.; PEREIRA, J.C.V.N.A.; MARTINS, A.L.M.; PAULO, E.M. Cultivares de amendoim: potencial produtivo, resistência e resposta ao controle de manchas foliares. Fitopatologia Brasileira, Brasília, v.19, p.288, 1994b. (Suplemento)

GODOY, I.J.; MORAES, S.A.; SIQUEIRA, W.J.; PEREIRA, J.C.V.N.A.; MARTINS, A.L.M.; PAULO, E.M. Produtividade, estabilidade e adaptabilidade de cultivares de amendoim em três níveis de controle de doenças foliares. Pesquisa Agropecuária Brasileira, Brasília, v.37, n.7, p.1183-1191, 1999a.

GODOY, I.J.; MORAES, S.A.; TURATTI, J.M.; PEREIRA, J.C.V.N.A.; MARTINS, A.L.M.; PAULO, E.M. IAC Caiapó: novo cultivar de amendoim. Campinas: Instituto Agronômico, 1996. 6p. (Fôlder)

GODOY, I.J.; MORAES, S.A.; ZANOTTO, M.D.; SANTOS, R.C. Melhoramento do amendoim. In: BORÉM, A. (Ed.). Melhoramento de espécies cultivadas. Viçosa: UFV, 1999b. p.51-94.

INSTITUTO AGRONÔMICO (CAMPINAS). Cultivar de amendoim IAC-Tatu-ST. Campinas: Instituto Agronômico, 2000. 4p. (Fôlder)

KRAPOVICKAS, A.; GREGORY, W.C. Taxonomy of the genus Arachis (Leguminosae). Bonplandia, Corrientes, Argentina, v.8, n.1-4, p.1-186, 1994.

MORAES, S.A. Escalas diagramáticas para avaliar a intensidade das cercosporioses do amendoim. O Agronômico, Campinas, v.39, n.1, p.9-18, 1987.

MORAES, S.A.; GODOY, I.J.; GERIN, M.A.N. Avaliação de resistência de Arachis hypogaea a Puccinia arachidis, Sphaceloma arachidis e Phoma arachidicola. Fitopatologia Brasileira, Brasília, v.8, p.499-506, 1983.

MORAES, S.A.; GODOY, I.J.; MARTINS, A.L.M.; PEREIRA, J.C.V.N.A.; PEDRO JÚNIOR, M.J. Epidemiologia da mancha-preta (Cercosporidium personatum) em amendoim: resistência, controle químico e progresso da doença. Fitopatologia Brasileira, Brasília, v.19, n.4, p.532540, 1994.

POMPEU, A.S. IAC Oirã, IAC Poitara e IAC Tupã: novos cultivares de amendoim para o Estado de São Paulo. Bragantia, Campinas, v.46, n.1, p.127-131, 1987.

RUSSELL, G.E. Pathogenic fungi and fungal diseases. In: Plant breeding for pest and disease resistance. London: Butterworths, 1978. p.47-82. (Studies in the Agricultural and Food Sciences)

ZANOTTO, M.D. Botutatu: nova cultivar de amendoim (Arachis hypogaea L.). Pesquisa Agropecuária Brasileira, Brasília, v.28, p.1101-1102, 1993. 